\title{
Canine subcutaneous dirofilariosis - noteless and neglected (Difficulties in disease monitoring)
}

\author{
M. MITERPÁKOVÁ, A. IGLÓDYOVÁ, Z. HURNÍKOVÁ
}

\begin{abstract}
Institute of Parasitology, Slovak Academy of Sciences, Hlinkova 3, 04001 Košice, Slovakia,
\end{abstract} E-mail:miterpak@saske.sk

\begin{abstract}
Summary
In Central Europe, several new endemic regions of subcutaneous dirofilariosis caused by filarial nematode Dirofilaria repens were identified during recent years. Among those countries is also Slovakia, where the infection in dogs was recorded for the first time in 2005. We summarize here the activities intended to increase the veterinarian's awareness of dirofilariosis and problems connected with establishing cooperation in monitoring of the infection in Slovakia. We also present the results of the questionnaire survey of public (foremost dog breeders and owners) knowledge on dirofilariosis.

Our experience shows that despite the fact that the disease was discovered in Slovakia already 6 years ago, veterinarians still do not attach adequate importance and attention to it. Out of over 540 veterinarians, who have been repeatedly requested to cooperate, only 26 were willing to engage in the monitoring programme. Surprisingly, we noticed much higher interest from the general public and dog owners: $53.1 \%$ of responders indicated that they had already heard about dirofilariosis and $45.2 \%$ of them knew about the risk of transmission to humans. But as many as $78.9 \%$ of animal owners pointed out, that they were not informed by their veterinarian about the possibilities of testing and prevention.

Nevertheless, in spite of multiple negative experiences, it is necessary to continue the monitoring of dirofilariosis given that the real distribution of the parasite in Slovakia is still unknown, which prevents the introduction of effective preventive measures.
\end{abstract}

Keywords: Canine dirofilariosis; monitoring; prevention

\section{Introduction}

In recent decades, epidemiologists worldwide have been experiencing a significant increase in occurrence and rapid spread of infections with zoonotic potential. This pheno- menon is related especially to the vector-borne diseases. From the group of parasitic infections, subcutaneous dirofilariosis caused by filarial nematode Dirofilaria repens gains the forefront in spreading rate. Definitive hosts of the parasite are dogs and free living carnivores, the role of intermediate host and simultaneously vector play different mosquito species. Man is included into the parasite lifecycle as an incidental host.

Dirofilariosis was even a decade ago considered as disease typical of southern European countries with subtropical climate (Italy, Greece, Spain, and Portugal) (Lefkaditis et $a l ., 2010)$ and in northern countries only sporadic cases of imported canine dirofilariosis were recorded. Nevertheless, during the last 5 years a significant reversal has occurred and autochthonous infections in Eastern and Central Europe (Serbia, Croatia, Hungary, Romania, Netherlands, Switzerland, and the Czech Republic) have been reported (Genchi et al., 2011). These countries also included Slovakia, where the parasite was for the first time diagnosed in dogs in 2005 (Svobodová et al., 2005).

Canine population serves as a reservoir of infection for humans and considering the zoonotic pattern of dirofilariosis, the monitoring of parasitic agent incidence is highly eligible. However, the monitoring programmes in regions where the infection is newly emerging are often tackling with plural challenges, from the lack of experienced specialists to sceptical or disregardful attitude of responsible authorities.

Epidemiological research of dirofilariosis in Slovakia was initiated in 2007. Within the first monitoring, endemic regions were identified where average prevalence rates in dogs exceeded 34.0 \% (Miterpáková et al., 2008; 2010) and the first four human cases of subcutaneous dirofilariosis with affirmed autochthonous origin were diagnosed (Babál et al., 2008; Ondriska et al., 2010; Nováková et al., 2011; Hrčková et al., in press).

Within the first epidemiological research multiple activi- 
ties were carried out with a view to inform and educate veterinarians, breeders and lay public about this zoonotic infection. Despite the effort, time and finance spent on, the information goes beyond awareness only with difficulty and dirofilariosis is even 6 years after its first emergence in Slovakia regarded by veterinary and human surgeons as almost "an exotic disease".

The present study demonstrates the problems connected with monitoring of the emerging infection and discusses the plausible solutions.

\section{Materials and methods}

In the frame of the first epidemiological research on subcutaneous dirofilariosis in Slovakia, three kinds of activities were initiated in order to obtain the largest possible number of canine blood samples, to determinate the real prevalence of dirofilariosis in our territory, and to implement an effective prevention to avoid spreading of the parasite.

\section{Activities aimed at increasing professional awareness of} veterinarians and dog breeders

- During 2007 - 2011 we published in total 15 professional and popular-scientific articles on dirofilariosis in Slovak periodicals.

- The information brochures apprising with the disease and possible prevention were issued in cooperation with two pharmaceutical companies. Brochures were sent to all veterinarians registered in the Chamber of Veterinary Surgeons of the Slovak Republic.

- More than 540 general practice veterinarians from all regions of Slovakia were addressed in writing and via e-mail with the offer of free testing of canine patients for dirofilariosis. The proposal included free provision of blood collection kits.

- Once or twice each year we held press conferences on the subject and several times yearly we participated in talk shows in televisions and radios.
- We created a web site providing all information on infection, its agents, transmission, therapy and prophylaxis. Interested person can find contact information free of charge examination of dogs and cats for dirofilariosis and procedures for sampling and shipment of samples (http://dirofilarioza.webnode.sk). Link to this site has been promulgated on numerous portals designed for dog and cat breeders and owners.

Survey on public knowledge of risk and prevention of subcutaneous dirofilariosis

In 2010 the questionnaire was designed to determine the public awareness (in particular in group of dog breeders and owners) about dirofilariosis. The questionnaire was placed on above mentioned website and several dog breeders' portals. Printed form was used to survey the foreknowledge of participants in international dog show held in February 2011 in Košice, Slovakia.

The questionnaire was designed to seek data under the essential categories:

1. personal data (age, sex)

2. details of pets at home

3. respondents knowledge of canine dirofilariosis and prevention

Category 3 included following questions:

- Have you heard about dirofilariosis disease?

- Has your vet informed you about the possibility of screening for dirofilariosis and its prevention?

- Do you think that dirofilariosis is a health risk for humans?

- Do you protect your pets during mosquito season using insecticide preparations?

Do you protect yourself during mosquito season using repellents?

\section{Results}

Out of over 540 addressed veterinarians and clinics, 26 participate in cooperation and monitoring of dirofilariosis.

Table 1. Results of public knowledge survey of dirofilariosis

\begin{tabular}{|c|c|c|c|}
\hline Question & response & $\mathrm{n}$ & $\%$ \\
\hline \multirow{2}{*}{ Have you heard about dirofilariosis disease? $(\mathrm{N}=527)$} & yes & 280 & 53.1 \\
\hline & no & 247 & 46.9 \\
\hline \multirow{2}{*}{$\begin{array}{l}\text { Has your vet informed you about the possibility of screening for dirofilariosis } \\
\text { and its prevention? } *(\mathrm{~N}=383)\end{array}$} & yes & 81 & 21.1 \\
\hline & no & 302 & 78.9 \\
\hline \multirow{2}{*}{ Do you think that dirofilariosis is a health risk for humans? $(\mathrm{N}=527)$} & yes & 238 & 45.2 \\
\hline & no & 289 & 54.8 \\
\hline \multirow{2}{*}{$\begin{array}{l}\text { Do you protect your pets during mosquito season using insecticide } \\
\text { preparations? } *(\mathrm{~N}=383)\end{array}$} & yes & 278 & 72.6 \\
\hline & no & 105 & 27.4 \\
\hline \multirow[t]{2}{*}{ Do you protect yourself during mosquito season using repellents? $(\mathrm{N}=527)$} & yes & 310 & 58.8 \\
\hline & no & 217 & 41.2 \\
\hline
\end{tabular}

$\mathrm{N}=$ number of individuals responding the question

* $(\mathrm{N}=383)=$ the question answered pet owners only

$\mathrm{n}=$ number of responses in the category 
Only 9 of them send samples for testing on a regular basis. On an average 25 visitors in a day open the website. The sup-pages devoted to therapy, prevention and diagnostics of the disease are the most frequently visited.

\section{Public knowledge of canine dirofilariosis in Slovakia}

In our questionnaire survey in total 527 respondents participated: 168 (37.9\%) males and 359 (68.1\%) females. Majority of the respondents belonged to the age category $25-45$ years $(52.6 \%), 161(30.5 \%)$ were younger than 25 years and $89(16.9 \%)$ older than 45 years.

Up to $85.2 \%$ partakers indicated that they owned a pet. 383 individuals had one or more dogs, which represent $72.7 \%$.

Answer report regarding the disease and prevention are summarised in Table 1. Questions No. 2 and No. 4 were answered by pet owners only.

\section{Discussion}

Respondents of our survey were mainly numbered among active dog breeders and owners (the majority of questionnaires were completed by participants in dog shows), as evidenced by obtained results: more than half of the respondents have already heard of dirofilariosis, almost $50 \%$ knew about the risk of the disease transmission to humans and more than $72 \%$ of the individuals indicated that they protected their pet against mosquitoes.

A much bigger problem constitutes the attitude of veterinarians. The answers of the respondents - pet owners, who more or less regularly attend appointments in veterinary ambulance, revealed that only $21 \%$ of them were informed by veterinarian about the risks and preventive measures against dirofilariosis. Nearly $79 \%$ of pet owners responded that their veterinarian had never informed them about the possibility of testing for dirofilariosis, neither about preventive measures.

The indifferent approach of veterinarians to this issue is proved by the fact that only 26 (less than $5 \%$ ) of 540 addressed practitioners were disposed to participate in dirofilariosis monitoring in dogs in Slovakia. This attitude affects the integral epidemiological research very negatively and complicates the implementation of preventive measures, which facilitates the uncontrolled spread of infection. To the sampling problem contributes to some extent also the fact that the subcutaneous dirofilariosis is not an obvious health problem, since this form is scarcely manifested by any specific clinical symptoms that would require an immediate medical solution.

Despite the above-mentioned negative experiences, we managed to establish a close cooperation with the head veterinary surgeons of Home Office SR and Department of Defense SR. Due to their responsible approach we were able to investigate all police and military dogs bred in Slovakia in the period 2005 - 2008. The average prevalence of subcutaneous dirofilariosis in police dogs reached $20.0 \%$, with $39.6 \%$ and $53.6 \%$ respectively, in the two hottest regions (Miterpáková et al., 2010).

Intensive cooperation with police veterinarians continued also by introducing the preventive measures - all police dogs were equipped with antiparasitic collars containing the insecticide deltamethrin (Scalibor ${ }^{\circledR}$ Protectorband) and during the mosquito season, they were administered by preparations containing active substance moxidectin, or ivermectin. The effectiveness of these measures was collated by repeated examination of all police dogs in the years $2009-2011$. We reported a significant decrease in dirofilariosis prevalence in this group of animals with the average of $4 \%$ to $6 \%$ of specimen infected during three years under study. These data strongly point out the importance of prevention and last but not least also the relevance of joint action of veterinary practitioners and parasitologists.

Although the epidemiological research on dirofilariosis in Slovakia has been on-going since 2007, hitherto the real parasite distribution is unknown. The southern parts of Slovakia bordering Hungary and Austria, where the average prevalence varies around $30 \%$ (Miterpáková et al., 2008), are studied relatively in detail. We have not been able to obtain statistically sufficient number of samples from other regions; actually from some districts no samples were examined up to date. Considering the described problems, the modification of sample collection method is advisable in future. We already began to address dog-shelters and hunting associations, where we have bootstrapped the blood sampling. Simultaneously, we pursue more intense impact on dog owners to ask their veterinarian for dirofilariosis testing. Indeed, dirofilariosis represents in particular veterinary health problem and therefore we aspire to establish and intensify the liaison with veterinary practitioners. We appreciate that the disease emerged in our country only recently and it will take some time until it will definitely embed in professional and lay awareness.

\section{Acknowledgements}

We thank to Mrs. Henrieta L. Urban for language revision. The work was realized within the frame of project funded by the Science Grant Agency VEGA 2/0011/12.

\section{References}

BABÁl, P., KobzovÁ, D., NovÁK, I., DubinskÝ, P., JALILI, N. (2008). First case of cutaneous human dirofilariosis in Slovak Republic. Bratisl. Lek. Listy, 109: 486 - 488

GENCHI, C., KRAMER, L.H., RIVASI, F. (2011). Dirofilarial infections in Europe. Vector Borne Zoonotic Dis., 11: 1307 - 1317. DOI: 10.1089/vbz.2010.0247.

HrČKOVÁ, G., KuChtovÁ, H., MiterpákOVÁ, M., ONDRISKA, F., CIBÍČEK, J., KOVACS, Š. (2012). Histological and molecular confirmation of the fourth human case caused by Dirofilaria repens infection in new endemic region Slovakia. J. Helminthol., in press. DOI: 10.1017/S0022149X12000077

LeFKaditis, M., Koukeri, S., CozMA, V. (2010): An endemic area of Dirofilaria immitis seropositive dogs at the eastern foothills of Mt Olympus, Northern Greece. Hel- 
minthologia, 47: 3 - 7. DOI: 10.2478/s11687-010-0001-3 MiterpÁKovÁ, M., AntolovÁ, D., HurníkovÁ, Z., DUBINSKÝ, P. (2008). Dirofilariosis in Slovakia - a new endemic area in Central Europe. Helminthologia, 45: $20-$ 23. DOI: $10.2478 / \mathrm{s} 11687-008-0003-6$

MiterpákovÁ, M., AntolovÁ, D., HurníkovÁ, Z., DUBINSKÝ, P., PAVlaČKA, A., NÉMETH, J. (2010). Dirofilaria infections in working dogs in Slovakia. J. Helminthol., 84: 173 - 176. DOI: 10.1017/S0022149X099990496 NovÁKovÁ, E., KINČEKOVÁ, J., ADAMICOVÁ, K., KompaníKOVÁ, J., ŠVIHROVÁ, V., ŠIMEKOVÁ, K., KRAUSE,

RECEIVED FEBRUARY 22, 2012
J., PavlínovÁ, J., DvorožŇÁkovÁ, E. (2011). Human Dirofilariosis: The report subcutaneous Dirofilaria repens infection in the Slovak Republic. Helminthologia, 48: 13 16. DOI: $10.2478 / \mathrm{s} 11687-011-0003-9$

ONDRiskA, F., LENGYel, D., MiterPÁKOVÁ, M., LENGYELOVÁ, B., StrehÁrovÁ, A., DubinskÝ, P. (2010). Human Dirofilariosis in the Slovak Republic - A case report. Ann. Agric. Environ. Med., 17: $169-171$

Svobodová, S., Svobodová, Z., Beladičová, V., VALENTOVÁ, D. (2005). First case of canine dirofilariasis in Slovakia: a case report. Vet. Med.-Czech, 50: 510 - 512 